\section{A Vertically Installed, Flush-mounted Tensiometer for Turfgrass Research}

\author{
R.E. Gaussoin ${ }^{1}$, J.A. Murphy', and B.E. Branham ${ }^{3}$ \\ Department of Horticulture, Kansas State University,' Manhattan, \\ KS 66506
}

Additional index words. soil water potential, manometer, pressure transducer

\begin{abstract}
A method for measuring soil water potential in field soils was adapted for use in turfgrass soils. The system uses tensiometers installed flush with the soil surface and permits a measuring depth as shallow as 2.5 to $5.0 \mathrm{~cm}$. Water potential within a tensiometer was measured with a portable pressure transducer. Linear relationships between water potential measured with mercury manometers or vacuum gauge-equipped tensiometers and the pressure transducer were obtained $\left(r^{2}=0.99\right.$ and 0.97 , respectively). The system accurately measures soil water potential of turfgrass soils, while permitting routine cultural practices to be performed.
\end{abstract}

The primary use of tensiometers in turfgrass water relations research has been as sensing devices for irrigation system control (Augustin and Snyder, 1984; O'Neil and Carrow, 1982; Younger et al., 1981). The use of tensiometers for development of turf soil-water characteristic curves, diurnal soilwater flux, and other important soil-water phenomena has been limited. The underutilization of tensiometers in turfgrass research is due to several factors. The shallow rooting of most turfgrass species, particularly cool-season varieties, requires placement of tensiometers at depths $<30 \mathrm{~cm}$ and often as shallow as $5 \mathrm{~cm}$ (Marsh, 1969; Turgeon, 1985). Gauge-type tensiometers frequently are installed horizontally, with the gauge enclosed in a below-ground protective box (Marsh, 1969; Turgeon, 1985). This allows routine cultural practices, such as mowing or spraying, to be performed without having to remove the tensiometer. However, the protective box increases the cost and labor of the installation and also encumbers valuable plot space. Gauge-equipped tensiometers also are damaged easily, require careful maintenance, and are expensive when used in large quantities. Tensiometers attached to mercury manometers are inexpensive but require careful maintenance when installed in the field. The use of mercury manometers also creates a safety hazard. Furthermore, mercury manometer tensiometers must be removed to permit routine cultural practices.

Tensiometers installed flush with the soil surface that could accurately measure soil

Received for publication 1 Aug. 1989. Contribution no. 90-38-J. from the Kansas Agricultural Experiment Station. The cost of publishing this paper was defrayed in part by the payment of page charges. Under postal regulations, this paper therefore must be hereby marked advertisement solely to indicate this fact.

${ }^{1}$ Assistant Professor, Dept. of Horticulture, Kansas State Univ.

${ }^{2}$ Graduate Student, Michigan State Univ.

${ }^{3}$ Associate Professor, Dept. of Crop and Soil Sciences, Michigan State Univ., East Lansing, MI 48824. use in turfgrass research.

The tensiometer was constructed of clear acrylic tubing $(1.3 \mathrm{~cm}$ i.d. $\times 2.0 \mathrm{~cm}$ o.d.) attached with epoxy to a porous ceramic cup (Fig. 1). The length of the acrylic tubing can be adjusted for altering the depth of measurement of the tensiometer. The lower end of the acrylic tubing was sized with a 14mm (9/16 inch) drill bit to allow the neck of the ceramic cup to slide into the tubing. The upper end of the acrylic tubing was sealed with a $1.3 \mathrm{~cm}$ i.d. $\times 2.0 \mathrm{~cm}$ o.d. (at mouth) septum stopper.

The guiding tube of the portable transducer must be removed and replaced with a section of copper or PVC tubing. This modification is necessary because the original guiding tube (Marthaler et al., 1983) was designed for above-ground installation of the upper end of the tensiometers. The replacement tube must be sized to allow insertion of the needle into the septum stopper to just penetrate into the air gap of the tensiometer.

The pressure transducer system with these previously described modifications was evaluated by comparing its soil water potential measurements to readings taken from a mercury manometer connected directly to the tensiometer (Marthaler et al., 1983). The effective measuring depth was 2.5 to $5.0 \mathrm{~cm}$. The shallow measuring depth was obtained by sealing the bottom half of the ceramic cup with plastic tape and epoxy. Transducer readings for tensiometers installed at depths of 5 to $10 \mathrm{~cm}$ and 13 to $18 \mathrm{~cm}$ were compared to those from adjacent gauge-equipped tensiometers located at the same depths. A total of 56 and 113 measurements was obtained for the transducer/mercury manometer and transducer/gauge tensiometer comparison, respectively. Both comparisons were made in July/August of 1986 on a mature stand of perennial ryegrass (Lolium perenne L.) maintained at a $3.8-\mathrm{cm}$ mowing height.

The linear relationships between readings from mercury manometers or gauge tensiometers and pressure-transducer tensiometers are shown in Fig. 2. The minimal scatter of the points in the lower graph indicates that data obtained with the modified tensiometer installed at a depth of 2.5 to $5.0 \mathrm{~cm}$ were 


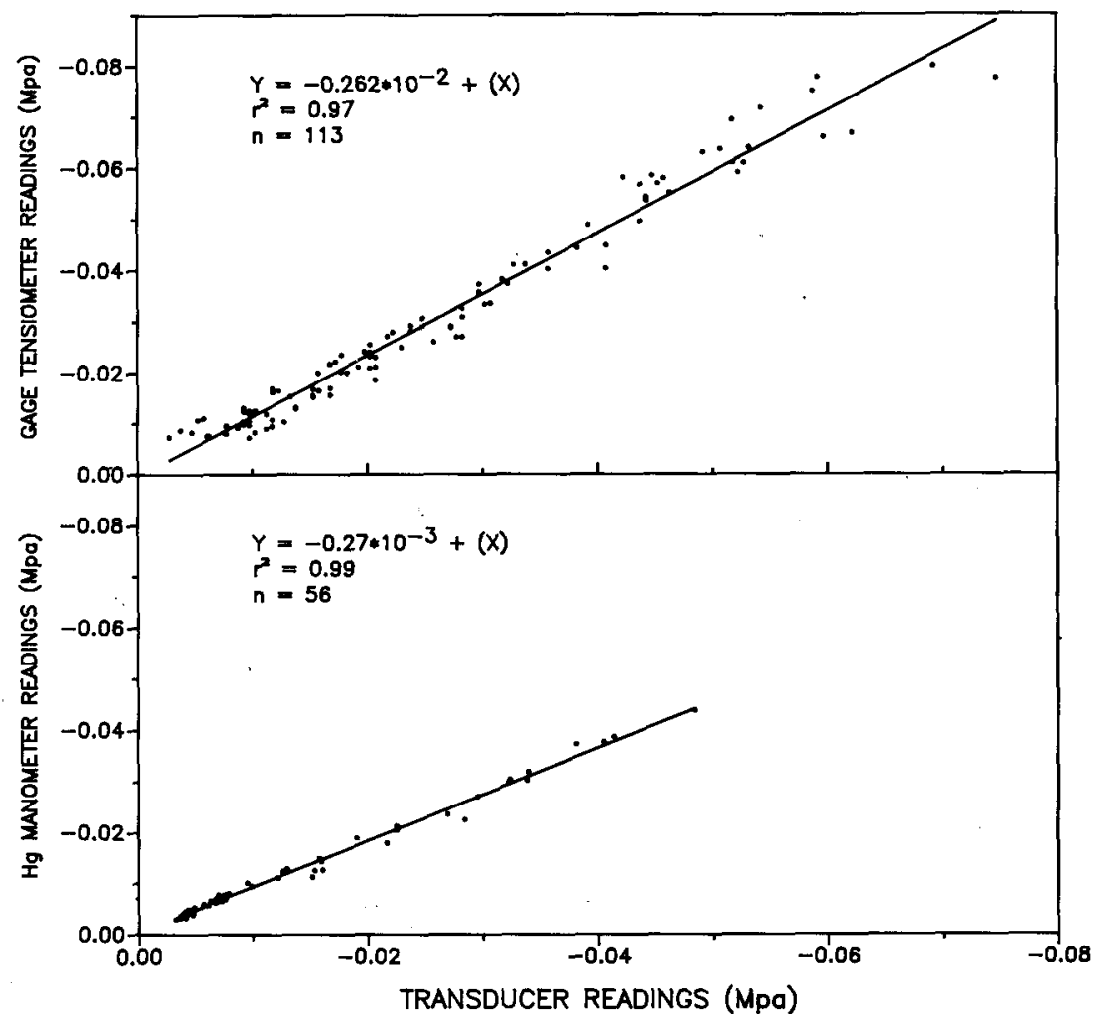

Fig. 2. Relationship between readings from mercury manometers (bottom) or gauge tensiometers (top) and pressure transducers installed in a stand of perennial ryegrass.

similar to mercury manometer data for the same depths. Installing tensiometers as shallow as 2.5 to $5.0 \mathrm{~cm}$ provided an excellent means of monitoring soil water status in the zone of greatest turfgrass root mass.

The comparison of the modified tensiometer with a gauge-equipped tensiometer at depths $>5 \mathrm{~cm}$ shows that there was more variation in the data from the gauge tensiometers (Fig. 2, top), probably a result of errors in gauge reading and/or gauge calibration and accuracy. However, the relationship was still significant.

When sizing the acrylic tubing to fit over the ceramic cup, the drill bit should be extremely sharp. The drilling operation should
The septa should be protected from sunlight to inhibit photodegradation. An empty 35$\mathrm{mm}$ film canister or PVC end cap works well for this purpose. Except for replacement of the septum, these tensiometers should have a life span typical of conventional tensiometers. The described system has been used for several years to measure soil moisture on a bentgrass green mowed at $0.6 \mathrm{~cm}$, a Kentucky bluegrass turf maintained at $3.8 \mathrm{~cm}$, and an annual bluegrass fairway mowed at $1.3 \mathrm{~cm}$. As long as the tensiometers were mounted just below thatch layer, level with the soil surface, no mechanical damage occurred from repeated traffic from machinery.

The tensiometer described herein is inexpensive in comparison to gauge-equipped tensiometers and will not interfere with routine cultural practices. The effective range of accurate soil water potential measurements of the modified tensiometers would be the range typical of conventional tensiometers, Although the initial cost of the system is high because of the expense of the transducer, the investment can be recovered from the decreased cost of the individual tensiometers.

\section{Literature Cited}

Augustin, B.J. and G.H. Snyder. 1984. Moisture sensor-controlled irrigation for maintaining bermudagrass turf. Agron. J. 76:848-850.

Marsh, A.W. 1969. Soil water-irrigation and drainage. In: A.A. Hanson and F.V. Juska (eds.). Turfgrass science. Agronomy 14:151-179.

be done slowly to avoid overheating and distortion of the acrylic tubing. If the acrylic tubing is distorted, the seal between the ceramic cup and tubing might cause air-entry problems. After installation, the water level in the tensiometers can be maintained without removal of the septum by filling with a medical syringe. If a medical syringe is used, a positive pressure will be exerted on the tensiometer, so the tensiometer will have to re-equilibrate with the soil water before additional readings are taken. The septa should be replaced after 50 to 75 readings to avoid air-entry problems. The life of the septum may be increased by a thin application of silicone sealant around the needle entry point.
Marthaler, H.P., W. Vogelsanger, F. Richard, and P.J. Wierenga. 1983. A pressure transducer for field tensiometers. Soil. Sci. Soc. Amer. J. 47:624-627.

O'Neil, K.J. and R.N. Carrow. 1982. Kentucky bluegrass growth and water use under different soil compaction and irrigation regimes. Agron. J. 74:933-936.

Turgeon, A.J. 198.5. Turfgrass management. Reston, Reston, Va. p. 184-185.

Younger, V.B., A.W. Marsh, R.A. Strohman, V.A. Gibeault, and S. Spaulding. 1981. Water use and turf quality of warm-season and coolseason turfgrasses. Proc. Intl. Turf Res. Conf. 4:251-257. 